tions to authors (printed in full in the first issue of every year and latterly, abbreviated, in the News pages every week). We do not want to impose handling charges for every article and page changes for the accepted paper, because all these would do is deprive medicine of much needed funds for research. Nevertheless, eventually we and many other journals may be forced by economic considerations to decline to consider for publication any article that does not use the standard conventions.

1 British Medical fournal, 1977, 2, 1428.

Williams, P C, Units, Symbols, and Abbreviations, ed G Ellis, p 35. London Royal Society of Medicine, 1972.

Ner" England fournal of Medicine, 1970, 282, 48

1 IUB Commission of Editors of Biochemical Journals, Biochemical fournal, 1973, 135, 1 .

Garfield, E, Nezi Scientist, 1968, 39, 565

O'Connor, M, British Medical fournal, 1978, 1, 31.

Smith, J, British Medical fournal, 1978, 1, 222.

\section{Ebstein's anomaly}

Ebstein's anomaly of the tricuspid valve ${ }^{1}$ is one of the rarer congenital cardiac malformations. Attention has been called to it in two recent articles: one showed that the prognosis was generally good with conservative management, ${ }^{2}$ while the other showed the feasibility of surgical treatment. ${ }^{3}$

The basic anomaly is a downward displacement of the attachment of the base of the tricuspid valve from the true valve ring into the cavity of the right ventricle. The medial and inferior leaflets are those most frequently affected, but sometimes the whole valve is displaced. ${ }^{4}$ As a result of the displacement the right ventricle is divided by the tricuspid valve into a distal, effective ventricle and a proximal "atrialised" portion which is thin-walled and poorly contractile. While the thickness of the distal ventricle is usually normal in some instances it, too, is attenuated. The relative sizes of the cavities of the effective right ventricle and the atrialised portion depend on the degree of displacement of the valve, and this is extremely variable. ${ }^{4}$ The tricuspid valve usually shows additional abnormalities. The leaflets may be fused at their edges, sometimes leading to tricuspid stenosis, or they may be perforated and sometimes portions are entirely absent. ${ }^{6}$

Even in its simplest form Ebstein's anomaly is, then, of highly variable severity, depending on the degree of displacement and dysplasia of the valve and the size and function of the effective right ventricle. Even this is not the whole picture, since half the affected patients have additional cardiac abnormalities. The most common is atrial septal defect or patent foramen ovale. About $20^{\prime \prime}$ " have more serious abnormalities including ventricular septal defect, pulmonary stenosis or atresia, the tetralogy of Fallot, mitral stenosis, and corrected transposition of the great arteries. Finally there is a high incidence of cardiac arrhythmias, sometimes associated with Wolff-Parkinson-White type B pre-excitation.

The rarity of Ebstein's anomaly (less than 100 children per year in Britain) and the diversity of the lesions have made the assessment of its clinical course and natural history difficult. The presentation may be with an asymptomatic cardiac murmur, with an arrhythmia, with cyanosis due to a right to left shunt through an atrial septal defect or foramen ovale, or with congestive cardiac failure. The course of the disease depends on the severity of the basic tricuspid valve lesion and the presence or absence of associated cardiac abnormalities. ${ }^{78}$ Certain facts are evident. A poor prognosis is associated with presentation in the first year of life, almost half of such patients dying early. ${ }^{78}$ Once through this danger period the prospects for survival into adult life are good. ${ }^{2}$ Nevertheless, at any age the appearance of cyanosis indicates a poor prognosis, while the onset of congestive cardiac failure is a particularly grave sign, few patients surviving for more than a few years.

Fortunately, in older children and adults surgery is feasible. ${ }^{3}$ The procedure consists of tricuspid valve replacement, obliteration of the atrialised portion of the right ventricle, and closure of the patency of the atrial septum, if present. ${ }^{3} 9$ Surgical treatment is generally reserved for those patients with cyanosis or congestive cardiac failure, while asymptomatic patients are treated conservatively. This approach should maximise the chances of survival for adults and older children with Ebstein's anomaly; but the management of the highestrisk cases, the infants, remains an unsolved problem.

1 Ebstein, W, Archiv für Anatomie und Physiologie, 1866, 33, 238.

2 Fischer-Hansen, J, et al, Acta Medica Scandinavica, 1977, 201, 331.

${ }^{3}$ Jugdutt, B I, et al, fournal of Thoracic and Cardiovascular Surgery, 1977, 73, 20.

${ }^{4}$ Lev, M, et al, Archives of Pathology, 1970, 90, 334

${ }^{5}$ Genton, E, and Blount, S G, American Heart fournal, 1967, 73, 395.

' Becker, A E, Becker, M J, and Edwards, J E, Archives of Pathology, 1971, $\mathbf{9 1}, 167$.

Kumar, E A, et al, American fournal of Cardiology, 1971, 28, 84

Watson, H, British Heart fournal, 1974, 36, 417.

${ }^{9}$ Hardy, K L, et al, fournal of Thoracic and Cardiovascular Surgery, 1964, 48,927 .

\section{Treatment of osteoporosis}

As long ago as 1941 Albright and his colleagues suggested that postmenopausal osteoporosis in women is caused by oestrogen deficiency. ${ }^{1}$ Other possible contributory factors are a small skeleton at maturity, ${ }^{2}$ the calcium malabsorption of old age ${ }^{3}$ and a high-protein diet. ${ }^{4}$ 5 Bone mass may not be the only factor which determines bone strength. Old bone is more fully calcified than young, and this may explain why less energy is required to fracture bones in adults than in children. ${ }^{6}$ Racial differences may also be important: among women aged over 70 in Johannesburg those who are white fracture their necks of femur at least 10 times as frequently as those who are black -in spite of their having no less bone mass as estimated by metacarpal radiogrammetry. ${ }^{7}$

Osteoporotic patients have about $20 \%$ less bone than their normal peers, ${ }^{8}$ whereas in both groups the annual rate of renewal of old bone is only about $5^{\circ},{ }_{0}{ }^{9-11}$ This means that even if bone breakdown could be arrested completely with formation continuing unabated at least four years' treatment would be needed for the average patient with osteoporosis to regain a bone mass normal for her age. Even this is unattainable because a substantial fraction of new bone formation occurs in the Haversian systems of cortical bone and is necessarily preceded by bone breakdown. Furthermore, many treatments proposed for osteoporosis, such as oestrogens, calcium supplements, and thiazide diuretics, reduce turnover and would thereby delay recovery further. ${ }^{12-14}$

The two fundamentally different approaches to treatment are prevention and restoration. Prevention aims at reducing bone resorption so that formation can keep pace. Hormone replacement, calcium supplements, and vitamin D (together 